\title{
Evaluación de daños por heladas tardías en ensayos de procedencias de pino oregón introducidos en el norte de la Región Andino Patagónica Argentina*
}

\author{
Evaluation of damage by late frosts in provenances trials of Douglas-fir introduced \\ in Argentinian North Patagonia
}

\author{
ALEJANDRO MARTINEZ MEIER ${ }^{1}$, VICTOR MONDINO², LEONARDO GALLO $^{1}$ \\ ${ }^{1}$ EEA INTA Bariloche, Area Forestal, Unidad de Genética Forestal. C.C. 277, (8400), Bariloche, Argentina. \\ E mail: almarti@bariloche.inta.gov.ar, lgallo@bariloche.inta.gov.ar \\ 2 EEA Esquel, Campo Experimental Trevelin. C.C. 17, (9203), Trevelin. E mail: vmondino@correo.inta.gov.ar
}

\begin{abstract}
SUMMARY
The susceptibility to late frost of the seed source used for afforestations at the moment it is one of the main adaptatives characteristic limiting the increase of the planted area of Douglas-fir (Pseudotsuga menziesii (Mirb.) Franco) in Argentinien North Patagonia Region. In two provenances trials of this species we registered frost injury caused by absolute minimum temperature of $-7^{\circ} \mathrm{C}$ during spring. In both sites we found significant differences among treatments. We found a strong correlation between the percentage of frost injury and seed source longitude $(r=0.86)$ and with seed source altitude $(r=0.75)$ in the trail that registered the most rigorous minimum. In this trial we found also a weaker association with nursery mean heights $(r=0.55)$ and the origin latitude $(r=0.44)$. Considering that coastal origins are those of better potential growth, selection based only growth criteria could produce an indirect selection of susceptible genotypes. Finally we recommend the simultaneous evaluation of yield and susceptibility to be able to extend the specie cultivation towards other areas with increased frost risks.
\end{abstract}

Key words: Douglas-fir, genetic improvement, origin trials, frost, Patagonia, Argentine.

\section{RESUMEN}

La susceptibilidad a las heladas tardías de la fuente de semilla actualmente utilizada es una de las principales características adaptativas que limitan la ampliación del área de plantación de pino oregón (Pseudotsuga menziesii (Mirb.) Franco) en la Región Norpatagónica de la Argentina. En dos ensayos de procedencias de esta especie se registró el daño provocado por heladas de primavera de hasta $-7^{\circ} \mathrm{C}$ de mínima absoluta. En ambos ensayos se encontraron diferencias significativas entre los tratamientos. En el ensayo en el que se registraron mínimas más rigurosas pudieron establecerse correlaciones altamente significativas entre el porcentaje de daño por heladas con la longitud $(r=0,86)$ y altitud $(r=-0,75)$ del origen de la semilla, y una menor asociación con la altura media de las plantas en vivero $(r=0,55)$ y la latitud de origen $(r=0,44)$. Considerando que los orígenes costeros son los de mayor potencial de crecimiento, estos resultados indican que la selección en base a ese único criterio podría producir una selección indirecta de genotipos susceptibles. Finalmente se recomienda la evaluación simultánea de rendimiento y susceptibilidad para extender el cultivo de la especie hacia áreas de mayor riesgo de heladas.

Palabras clave: pino oregón, mejoramiento genético, ensayos de orígenes, heladas, Patagonia, Argentina.

* Programa de Producción de Material de Propagación Mejorado, Subregión Andino Patagónica para Coníferas y otras especies financiado por INTA y la Secretaría de Agricultura, Ganadería, Pesca y Alimentos, Proyecto Forestal de Desarrollo - BIRF, Convenio de Préstamo No 3948-AR. 


\section{INTRODUCCION}

La Región Andino Patagónica de la Argentina posee una superficie forestada estimada en 54.000 ha con especies de rápido crecimiento $(1,2)$, con proyecciones en la actualidad de más de 70.000 ha implantadas según datos de la Secretaría de Agricultura, Ganadería, Pesca y Alimentos (SAGPyA). Las especies más utilizadas son: Pinus ponderosa, Pinus contorta var. latifoliada y Pseudotsuga menziesii (pino oregón). Esta última es la que produce madera de mejor calidad y al momento de la cosecha final la mayor rentabilidad, alcanzando rendimientos superiores a los $30 \mathrm{~m}^{3} /$ ha año (3). Su extraordinaria adaptabilidad a la zona se refleja en valores máximos de Indice de Densidad de Reineke superiores a los que alcanza en su distribución natural en Norteamérica (4).

Sin embargo, pino oregón requiere mejores sitios que cualquier otra conífera implantada a escala comercial en la región. Los suelos deben ser profundos, bien drenados y, en general, sin limitaciones (5). También requiere protección de los vientos dominantes, y condiciones de humedad mayores a la de las otras coníferas mencionadas (6). Uno de los inconvenientes de la especie es su susceptibilidad a las heladas producidas durante el período de crecimiento $(7,8,9,10,11$, 12), fundamentalmente las que se producen en el año de instalación de la plantación.

La resistencia a las heladas particularmente en el estado de plántulas es una de las características adaptativas de mayor importancia a tener en cuenta dentro de los programas de selección o mejoramiento. En este estadio se presenta la mayor vulnerabilidad al efecto de las bajas temperaturas, siendo en muchos casos motivo de fracaso de las plantaciones de pino oregón.

Estas heladas originan necrosamiento de los brotes terminales, pudiendo llegar a producir daños importantes como malformaciones en el fuste o, en casos muy severos, la muerte de la planta. Sin llegar a estos extremos, el daño por heladas durante el período de actividad vegetativa afecta directamente el ritmo de crecimiento, disminuyendo la capacidad de la planta afectada para producir carbohidratos y asimilarlos en la producción de madera (13).

El área potencial de implantación con esta especie forestal en Argentina no se encuentra li- bre de heladas durante su período de crecimiento. Bustos (14) realizó una recopilación de datos para determinar el período libre de heladas en el Oeste de la Región Norpatagónica, abarcando desde Chos Malal $\left(37^{\circ} 23^{\prime} \mathrm{S}\right)$ hasta Gobernador Costa $\left(44^{\circ}\right.$ 03' S). Considerando las fechas de la primera y última helada del año divide a toda esta región en dos grandes zonas: la norte, con la primera helada el 21 de marzo y la última el 1 de diciembre, y la sur, con la primera helada el 23 de febrero y la última el 31 de diciembre. Sin embargo, dentro de cada zona, se verifican variaciones de 15 a 20 días para la fecha de primeras heladas y de 15 a 25 días para la fecha de últimas heladas (15). Esta variación no permite reconocer un patrón claro de diferenciación de norte a sur, pero sí en sentido oeste a este, encontrándose un mayor período libre de heladas en los sitios más occidentales. Esto se explica básicamente por la disminución de la humedad relativa y el aumento de la amplitud térmica hacia el este (14).

Ampliar el potencial de desarrollo y el área de implantación de pino oregón en la Región Andino Patagónica requiere la introducción de nuevas procedencias o fuentes de semillas más tolerantes a las heladas ocurridas durante el período de crecimiento. De este modo, los genotipos seleccionados representarían una alternativa productiva a competir en el vasto espacio estepario de la precordillera con especies de Pinus más rústicas y de menor calidad de madera.

La adaptación de las poblaciones naturales de pino oregón en su área de distribución natural podría interpretarse como un balance entre selección para alto potencial de crecimiento en ambientes suaves y selección para resistencia a heladas en ambientes severos (13). Por otro lado, la variabilidad genética de pino oregón es amplia y gran proporción de esa variación en la especie se halla a nivel intrapoblacional $(11,16)$. Varios autores reportan una alta variación en características adaptativas relacionadas con la resistencia a heladas dentro de poblaciones de alto potencial de crecimiento $(11,12,17)$.

La Unidad de Genética Forestal del Instituto Nacional de Tecnología Agropecuaria Bariloche inició en 1998 un Programa de Mejoramiento Genético de pino oregón a través del cual se realizó una introducción de procedencias certificadas por el USDA Forest Service. En los sitios de ensayos se registraron en la primavera avanzada del 
año de implantación fuertes heladas. Dada esta situación particular se estudió la respuesta a las bajas temperaturas soportadas.

En este estudio se reporta el comportamiento de las distintas procedencias y fuentes de semillas respecto al daño provocado por heladas primaverales sucedidas durante el primer período de crecimiento.

\section{MATERIAL Y METODOS}

Las semillas introducidas fueron viverizadas mediante el sistema tradicional de producción a raíz desnuda, en el vivero del Campo Forestal General San Martín de la EEA INTA Bariloche (Golondrinas, Chubut). Con este material de un año de almácigo y dos de repique en platabanda, se instalaron dos ensayos de procedencias durante el mes de agosto del año 2000.

Uno de ellos está ubicado en el Campo Experimental Trevelin (CET) de la Estación Experimental Agroforestal INTA Esquel (43 06' 33” S, $71^{\circ} 32^{\prime} 40^{\prime \prime} \mathrm{W}, 340 \mathrm{~m}$ s.n.m.). Presenta exposición sudeste, con una pendiente de $10^{\circ}$ a $15^{\circ}$. La vegetación predominante del sitio está constituida por matorrales de altura variable $(0,5 \mathrm{~m}$ a $2 \mathrm{~m})$, de especies de bosque secundario como pañil (Buddleja blobosa) y retamo (Diostea juncea) que fueron eliminadas al momento de la instalación del ensayo solo en las fajas de $1 \mathrm{~m}$ de ancho donde se realizó la forestación. Los bloques del diseño experimental fueron de forma rectangular $\mathrm{y}$ se dispusieron con el eje principal en forma perpendicular al sentido de la pendiente.

El otro ensayo se ubica en un predio privado en Mallín Ahogado (MA), en las cercanías de El

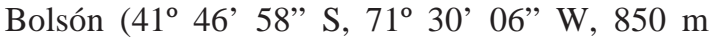
s.n.m.). Su exposición es sur-sudeste, con pendiente de $6^{\circ}$ a $7^{\circ}$. La vegetación es de matorral alto de ñires (Nothofagus antarctica), lauras (Schinus patagonicus), retamos (Diostea juncea) y maitenes (Maytenus boaria) en estado de regeneración avanzada luego de un incendio ocurrido en 1987 (la vegetación natural no fue removida). En este ensayo la mayor fuente de variación es la exposición, de manera que los bloques del diseño experimental se dispusieron de tal forma de controlar su influencia.

El material ensayado y evaluado incluye 15 procedencias de la región costera de los Estados
Unidos y de British Columbia, Canadá (Pseudotsuga menziesii var. menziesii), cinco del interior de la distribución natural correspondientes a ambientes secos y fríos (Pseudotsuga menziesii var. glauca), y dos fuentes semilleras provenientes de Programas de Mejoramiento Genético de Estados Unidos y Canadá, ambos de origen costero por sus características de forma y color de follaje. También se incluyeron dos testigos comerciales locales de origen desconocido de la var menziesii con alta probabilidad de proceder de los Estados de Washington y Oregon de los EE.UU. (18) (cuadro 1).

Según las mediciones realizadas en vivero antes de la plantación de los ensayos los orígenes costeros presentaban mayores crecimientos en altura que los orígenes del interior (cuadro 1). Un test de comparación de medias separó a estos dos grupos (ANDEVA y Tukey con $\alpha=5 \%$ ).

En el Campo Experimental Trevelin se utilizó el diseño de bloques completos al azar, mientras que en Mallín Ahogado se instaló el ensayo con bloques incompletos debido a que no se contaba con el material suficiente en algunos de los tratamientos. Ambos ensayos, con cuatro repeticiones, la unidad experimental de nueve plantas y el distanciamiento de plantación de $2 \mathrm{~m} \times 2 \mathrm{~m}$.

El 13 de noviembre del 2000 se produjo en el Campo Experimental Trevelin una nevada de importancia, registrándose en los días siguientes en la Estación Meteorológica del lugar un brusco descenso de temperatura, alcanzando una mínima absoluta de $-7^{\circ} \mathrm{C}$.

Durante el mes de enero de 2001 en ambos sitios se evaluó la presencia de daños visibles por las heladas tardías ocurridas en el mes de noviembre del año anterior. Para considerar que una planta había sido afectada se estableció que tuviera al menos un $30 \%$ de los brotes o yemas del año necrosados. En cada uno de los sitios se estableció el porcentaje de daño para cada tratamiento.

Se efectuó un análisis de varianza (ANDEVA) para probar el nivel de significancia estadística de las diferencias observadas entre los porcentajes medios de las plantas afectadas en cada tratamiento $(\alpha=5 \%)$. Posteriormente, a través del test de Tukey, se compararon los valores medios de los tratamientos sin diferencias significativas $(\alpha=5 \%)$.

Para determinar la existencia de asociación entre la ubicación geográfica de los orígenes (latitud, longitud y altitud) y el porcentaje medio de 


\section{CUADRO 1}

Lista de procedencias y fuentes de semillas de Pseudotsuga menziesii introducidos por la Unidad de Genética Forestal del INTA Bariloche indicando la altura promedio lograda al segundo año de repique en vivero.

List of provenances and seed sources of Pseudotsuga menziesii introduced by the Forest Genetic Unit of INTA Bariloche indicating the average height of the seedlings after the second growth at the nursery.

\begin{tabular}{|c|c|c|c|c|c|c|c|}
\hline ID local & ID Collect. & Zona & Variedad & Latitud & Longitud & $\begin{array}{c}\text { Altitud } \\
\text { m s.n.m. }\end{array}$ & $\begin{array}{l}\text { Altura media } \\
\qquad(\mathrm{cm})\end{array}$ \\
\hline 16 & DNR 158 & Seed Orchards & menziesii & - & - & - & 67,3 \\
\hline 15 & DNR 112 & Raymond, WA & menziesii & $46^{\circ} 42^{\prime} \mathrm{N}$ & $123^{\circ} 37^{\prime} \mathrm{W}$ & 150 & 66,6 \\
\hline 12 & DNR 042 & Quilcene, WA & menziesii & $47^{\circ} 49^{\prime} \mathrm{N}$ & $122^{\circ} 54^{\prime} \mathrm{W}$ & 100 & 64,3 \\
\hline 23 & PNW 3 & Eddyville, OR & menziesii & $44^{\circ} 40^{\prime} \mathrm{N}$ & $123^{\circ} 45^{\prime} \mathrm{W}$ & 50 & 61,9 \\
\hline 21 & PNW 4 & Lacomb, OR & menziesii & $44^{\circ} 35^{\prime} \mathrm{N}$ & $122^{\circ} 42^{\prime} \mathrm{W}$ & 275 & 60,7 \\
\hline 11 & DNR 032 & Rockport, WA & menziesii & $48^{\circ} 30^{\prime} \mathrm{N}$ & $121^{\circ} 37^{\prime} \mathrm{W}$ & 150 & 60,0 \\
\hline 13 & DNR 104 & Granite Falls, WA & menziesii & $48^{\circ} 00^{\prime} \mathrm{N}$ & $121^{\circ} 54^{\prime} \mathrm{W}$ & 150 & 59,0 \\
\hline 7 & DNR015 & Cathlamet, WA & menziesii & $46^{\circ} 11^{\prime} \mathrm{N}$ & $123^{\circ} 22^{\prime} \mathrm{W}$ & 40 & 58,5 \\
\hline 14 & DNR 013 & North Bend, WA & menziesii & $47^{\circ} 31^{\prime} \mathrm{N}$ & $121^{\circ} 54^{\prime} \mathrm{W}$ & 235 & 56,0 \\
\hline 17 & DNR 160 & Skamakawa, WA & menziesii & $46^{\circ} 21^{\prime} \mathrm{N}$ & $123^{\circ} 26^{\prime} \mathrm{W}$ & 250 & 55,1 \\
\hline 10 & DNR 030 & Clearwater, WA & menziesii & $47^{\circ} 39^{\prime} \mathrm{N}$ & $124^{\circ} 06^{\prime} \mathrm{W}$ & 450 & 52,3 \\
\hline 9 & DNR 021 & Stevenson, WA & menziesii & $45^{\circ} 39^{\prime} \mathrm{N}$ & $121^{\circ} 55^{\prime} \mathrm{W}$ & 150 & 51,2 \\
\hline 20 & $\mathrm{BC}-3$ & D'arcy, BC & menziesii & $50^{\circ} 33^{\prime} \mathrm{N}$ & $122^{\circ} 30^{\prime} \mathrm{W}$ & 270 & 34,0 \\
\hline 18 & $\mathrm{BC}-2$ & Lonesome Lake, BC & menziesii & $52^{\circ} 13^{\prime} \mathrm{N}$ & $125^{\circ} 42^{\prime} \mathrm{W}$ & 475 & 30,2 \\
\hline 19 & $\mathrm{BC}-4$ & Nahatlatch, BC & menziesii & $49^{\circ} 59^{\prime} \mathrm{N}$ & $121^{\circ} 29^{\prime} \mathrm{W}$ & 305 & 28,1 \\
\hline 25 & $\mathrm{BC}-1$ & Shuswaq Lake, BC & menziesii & $51^{\circ} 00^{\prime} \mathrm{N}$ & $119^{\circ} 38^{\prime} \mathrm{W}$ & 830 & 23,3 \\
\hline 27 & ID-4 & Idaho, ID & glauca & $44^{\circ} 30^{\prime} \mathrm{N}$ & $116^{\circ} 55^{\prime} \mathrm{W}$ & 1.525 & 9,4 \\
\hline 26 & MT-1 & Montana, MT & glauca & $48^{\circ} 30^{\prime} \mathrm{N}$ & $114^{\circ} 30^{\prime} \mathrm{W}$ & 1.050 & 8,9 \\
\hline 5 & A-56 & Wilson Creek & glauca & $46^{\circ} 53^{\prime} \mathrm{N}$ & $112^{\circ} 52^{\prime} \mathrm{W}$ & 1.645 & 8,5 \\
\hline 22 & $\mathrm{M}-22$ & Larry Creek, MT & glauca & $46^{\circ} 35^{\prime} \mathrm{N}$ & $114^{\circ} 10^{\prime} \mathrm{W}$ & 1.220 & 8,0 \\
\hline 3 & A-38 & Blind Creek & glauca & $44^{\circ} 30^{\prime} \mathrm{N}$ & $111^{\circ} 36^{\prime} \mathrm{W}$ & 1.950 & 6,5 \\
\hline 24 & $\mathrm{BC}-5$ & Coastal Elite Fam. & menziesii & - & - & - & \\
\hline $\mathrm{T} 1$ & & Semilla comercial & menziesii & $43^{\circ} 08^{\prime} \mathrm{S}$ & $71^{\circ} 34^{\prime} \mathrm{W}$ & 340 & - \\
\hline $\mathrm{T} 2$ & & Semilla comercial & menziesii & $42^{\circ} 00^{\prime} \mathrm{S}$ & $71^{\circ} 31^{\prime} \mathrm{W}$ & 300 & - \\
\hline
\end{tabular}

daño por heladas se efectuó un análisis de correlación, utilizando el coeficiente de correlación de Pearson. También se analizó la correlación de las variables geográficas y el daño promedio por heladas con la altura de las plantas en vivero, al momento de instalación de los ensayos de campo. Para el análisis de los datos se utilizó el paquete estadístico SAS (19).

\section{RESULTADOS Y DISCUSION}

La supervivencia del material de ensayo al momento de la evaluación del daño por heladas fue de 94,3\% en el Campo Experimental Trevelin (CET) y 99,9\% en Mallín Ahogado (MA).

En CET la intensidad del daño provocado por heladas fue mayor que en MA. En el primer sitio se observó en algunas plantas la muerte de la porción superior incluyendo la yema apical, mientras que en el segundo sitio el daño solamente afectó la porción de hojas nuevas de las yemas vegetativas.

Los porcentajes de daño fueron diferentes entre los distintos tratamientos en cada uno de los sitios de ensayo, con valores de $0 \%$ a $91,7 \%$ en CET y de $2,8 \%$ a $89 \%$ en MA. Las diferencias entre los tratamientos ensayados resultaron signi- 
ficativas en ambos sitios. El test de Tukey estableció el agrupamiento indicado en el cuadro 2.

El coeficiente de variación para la variable porcentaje de daño por heladas fue alto tanto en CET como en MA (55\% y 49\%, respectivamente). Esto podría explicar por qué los grupos formados con los resultados del Test de Tukey incluyan tratamientos con porcentajes de daño contrastantes $(91,7 \%$ y $22,2 \%$ en un grupo de CET).

El análisis de correlación arrojó asociaciones altamente significativas entre el daño por heladas tardías y las variables longitud y altitud de los orígenes en CET $(r=0,86$ y $-0,75$ respectivamente).

La variable longitud discrimina indirectamente las dos variables botánicas de la especie, que corresponden a los orígenes costeros y del interior. Estos últimos (Pseudotsuga menziesii var. glauca) y de ambientes altos se mostraron más resistentes. Sin embargo no hubo correlación con estas mismas variables en el otro sitio de ensayo (MA). También pudo establecerse en CET una correlación significativa entre el porcentaje de daño por heladas y la latitud $(r=0,44)$ (cuadro 3).

\section{CUADRO 2}

Comparación de medias en base al test de Tukey $(\alpha=5 \%)$ de los tratamientos evaluados en dos ensayos de campo según el porcentaje de daño provocado por heladas tardías.

Means comparison by the Tukey test $(\alpha=5 \%)$ of the treatments evaluated in two field trials according to percent of injury caused by late frost.

\begin{tabular}{|c|c|c|c|c|c|c|c|c|c|c|c|c|}
\hline \multicolumn{6}{|c|}{ Campo Experimental Trevelin } & \multicolumn{7}{|c|}{ Mallín Ahogado } \\
\hline \multirow{2}{*}{$\begin{array}{l}\text { ID local } \\
18\end{array}$} & \multirow{2}{*}{$\begin{array}{c}\% \text { de daño } \\
91,7\end{array}$} & \multicolumn{4}{|c|}{$\begin{array}{l}\text { Grupos con diferencias } \\
\text { no significativas }\end{array}$} & \multirow{2}{*}{$\begin{array}{c}\text { ID local } \\
7\end{array}$} & \multirow{2}{*}{$\begin{array}{c}\text { \% de daño } \\
89,9\end{array}$} & \multicolumn{5}{|c|}{$\begin{array}{l}\text { Grupos con diferencias } \\
\text { no significativas }\end{array}$} \\
\hline & & A & & & & & & A & & & & \\
\hline 17 & 82,6 & A & $\mathrm{B}$ & & & 19 & 72,3 & A & B & & & \\
\hline 20 & 75,0 & A & B & $\mathrm{C}$ & & 25 & 67,7 & A & B & & & \\
\hline 14 & 67,6 & A & B & $\mathrm{C}$ & $\mathrm{D}$ & 20 & 52,8 & A & B & $\mathrm{C}$ & & \\
\hline 10 & 67,4 & $\mathrm{~A}$ & B & $\mathrm{C}$ & $\mathrm{D}$ & 9 & 44,4 & A & B & $\mathrm{C}$ & $\mathrm{D}$ & \\
\hline 9 & 65.9 & A & B & $\mathrm{C}$ & $\mathrm{D}$ & 18 & 44,4 & A & B & $\mathrm{C}$ & $\mathrm{D}$ & \\
\hline 7 & 63,9 & A & $\mathrm{B}$ & $\mathrm{C}$ & $\mathrm{D}$ & 21 & 38,9 & & B & $\mathrm{C}$ & $\mathrm{D}$ & $\mathrm{E}$ \\
\hline $\mathrm{T} 1$ & 62,9 & A & B & $\mathrm{C}$ & $\mathrm{D}$ & 11 & 33,3 & & B & $\mathrm{C}$ & $\mathrm{D}$ & E \\
\hline 13 & 62,6 & A & B & $\mathrm{C}$ & $\mathrm{D}$ & 17 & 30,6 & & B & $\mathrm{C}$ & $\mathrm{D}$ & E \\
\hline 19 & 58,3 & A & B & $\mathrm{C}$ & $\mathrm{D}$ & $\mathrm{T} 2$ & 27,8 & & & $\mathrm{C}$ & $\mathrm{D}$ & E \\
\hline 12 & 51,2 & A & B & $\mathrm{C}$ & $\mathrm{D}$ & 22 & 27,8 & & & $\mathrm{C}$ & $\mathrm{D}$ & E \\
\hline 11 & 50,0 & A & B & $\mathrm{C}$ & $\mathrm{D}$ & 12 & 18,5 & & & $\mathrm{C}$ & $\mathrm{D}$ & E \\
\hline 15 & 49,0 & A & B & $\mathrm{C}$ & $\mathrm{D}$ & 26 & 16,7 & & & $\mathrm{C}$ & $\mathrm{D}$ & E \\
\hline 23 & 47,2 & A & B & $\mathrm{C}$ & $\mathrm{D}$ & 14 & 14,8 & & & $\mathrm{C}$ & $\mathrm{D}$ & E \\
\hline 25 & 41,7 & A & B & $\mathrm{C}$ & $\mathrm{D}$ & 13 & 13,9 & & & $\mathrm{C}$ & $\mathrm{D}$ & $\mathrm{E}$ \\
\hline 16 & 38,9 & A & B & $\mathrm{C}$ & $\mathrm{D}$ & 27 & 8,3 & & & & $\mathrm{D}$ & E \\
\hline 21 & 36,1 & A & B & $\mathrm{C}$ & $\mathrm{D}$ & 16 & 8,3 & & & & $\mathrm{D}$ & E \\
\hline 24 & 27,8 & A & B & $\mathrm{C}$ & $\mathrm{D}$ & 10 & 7,4 & & & & $\mathrm{D}$ & E \\
\hline 5 & 26,0 & A & B & $\mathrm{C}$ & $\mathrm{D}$ & 15 & 5,6 & & & & $\mathrm{D}$ & E \\
\hline 27 & 22,2 & A & B & $\mathrm{C}$ & $\mathrm{D}$ & 23 & 2,8 & & & & & E \\
\hline 22 & 20,1 & & B & $\mathrm{C}$ & $\mathrm{D}$ & & & & & & & \\
\hline 26 & 5,6 & & & $\mathrm{C}$ & $\mathrm{D}$ & & & & & & & \\
\hline 3 & 0,0 & & & & $\mathrm{D}$ & & & & & & & \\
\hline
\end{tabular}




\section{CUADRO 3}

Coeficientes de correlación de Pearson (y valores de significancia) entre las variables \% de daño en el sitio CET, \% de daño en el sitio MA, altura promedio (vivero) y latitud, longitud y altitud de cada procedencia. Correlations coefficients of Pearson (and significance value) between the \% of injury in site CET, \% of injury in site MA, means heights (at the nursery) and latitude, longitude and altitude of each provenances.

\begin{tabular}{|lcccccc|}
\hline & \% daño CET & \% daño MA & Alt. Prom & Latitud & Longitud & Altitud \\
\hline \% daño CET & & 0,28 & 0,55 & 0,44 & 0,86 & $-0,75$ \\
& & $(0,2416)$ & $(0,0092)$ & $(0,0498)$ & $(<, 0001)$ & $(<, 0001)$ \\
\% daño MA & 0,28 & & $-0,19$ & 0,39 & 0,10 & $-0,14$ \\
Alt-prom & $(0,2416)$ & & $(0,4153)$ & $(0,1021)$ & $(0,6707)$ & $(0,5600)$ \\
& 0,55 & $-0,19$ & & $-0,11$ & 0,82 & $-0,89$ \\
& $(0,0092)$ & $(0,4153)$ & & $(0,6323)$ & $(<, 0001)$ & $(<, 0001)$ \\
\hline
\end{tabular}

En cursiva las correlaciones significativas

Significant correlations in italic.

En MA los valores de temperatura no alcanzaron los niveles extremos de $\operatorname{los}-7^{\circ} \mathrm{C}$ registrados en CET. La mayor rigurosidad de las heladas (mayor presión de selección) ocurridas en CET permitió una expresión mayor de los genotipos y por lo tanto establecer asociaciones claras entre los distintos orígenes y procedencias ensayados en el sitio. En MA el grado de cobertura vegetal es mayor y la misma podría estar actuando como una protección sobre las plantas de pino oregón.

La figura 1 muestra la separación de los orígenes costeros y del interior en función de la longitud y altitud (m) de acuerdo a su susceptibilidad a las heladas producidas en CET.

Asimismo, en base a las alturas medidas en vivero se pudo establecer una alta correlación entre altura de las plantas y las variables longitud y altitud $(r=0,82$ y $-0,89)$ respectivamente (cuadro 3), de tal modo que los orígenes del interior y los de mayor altitud resultaron ser los más resistentes $\mathrm{y}$, al mismo tiempo, los de menor crecimiento en altura en la etapa inicial de vivero.

En el sitio de ensayo con mayor daño por heladas, las plantas de menor altura promedio resultaron ser las más resistentes a las heladas tardías $(r=0,55)$. Ya se ha sugerido que el retraso del inicio de la brotación y el temprano cierre del crecimiento reducen los riesgos de daños por heladas $(9,13,17)$, Kuser y Ching citados por O'Neill et al. (11). De este modo, un período de crecimiento menor, provocado por inicio de brotación más tarde y un cierre del crecimiento más temprano trae como consecuencia una resistencia indirecta al fenómeno por medio de un mecanismo de escape. Valores de asociación me$\operatorname{dios}(r=0,50)$ entre altura al cuarto año y el cierre del período de crecimiento fueron reportados para pino oregón por Rehfeldt (9).

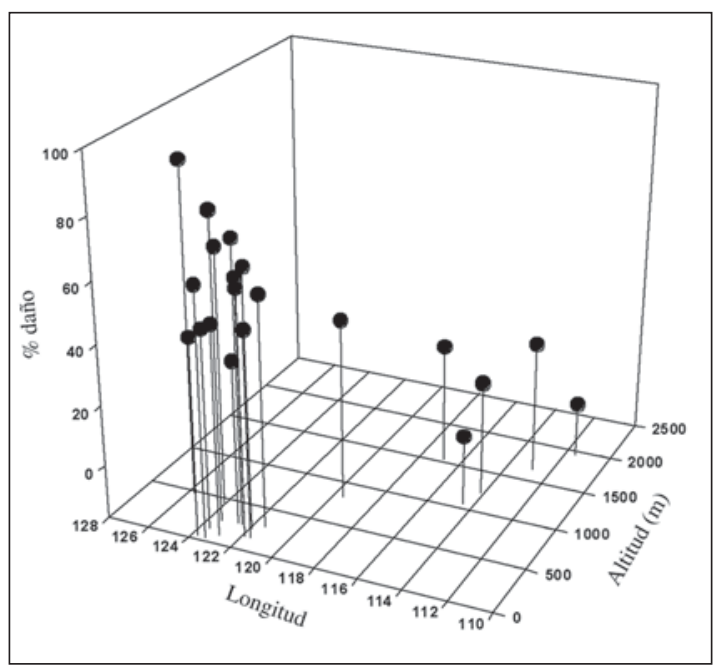

Figura 1. Relación entre el porcentaje de daño por heladas tardías con la longitud y altitud de las procedencias de semilla ensayadas, para la situación del Campo Experimental Trevelin (CET).

Relationships between the percentage of injury caused by late frosts and the longitude and altitude of the provenances, for the trial of Campo Experimental Trevelin (CET). 
La selección por alto potencial de crecimiento origina una selección negativa de las características de tipo adaptativas relacionadas con la resistencia a heladas tempranas y tardías $(9,13)$. La introducción de orígenes de sitios elevados (sin períodos libre de heladas) o de climas mediterráneos mejoraría las características adaptativas de resistencia a heladas, pero implicaría una reducción muy importante del potencial de crecimiento. Parcelas demostrativas, instaladas en el Campo Forestal General San Martín, muestran que los orígenes costeros de la var. menziesii duplican en crecimiento a los orígenes del interior de los EE.UU. de la var. glauca (datos sin publicar).

Las procedencias que han demostrado el mayor crecimiento en altura en vivero al segundo año se mostraron más susceptibles al daño provocado por las heladas tardías. Por otro lado, altos valores de heredabilidad individual en sentido estricto y varianza genética aditiva para resistencia a heladas tardías han sido reportados para poblaciones de origen costero de bajas a medianas altitudes (11). Esto indicaría que sería muy efectiva la búsqueda en forma conjunta de genotipos (individuos) resistentes al daño por heladas tardías o tempranas y potencial de crecimiento entre las poblaciones de la var menziesii (costeras) que puedan adaptarse a las condiciones adversas mesoclimáticas del área potencial de implantación de pino oregón en la Región Andino Patagónica.

Hattemer y Konig (7) plantean que algunos individuos pueden escapar al daño por heladas debido a la particularidad de su fenología y que el daño por heladas tardías no está necesariamente asociado a brotación temprana. Rehfeldt (9) indica que el inicio de la brotación se muestra independiente del cierre de crecimiento y del potencial de crecimiento; sin embargo, encuentra que daños provocados por heladas tempranas también están asociados a daños por heladas tardías. En el presente trabajo las procedencias de pino oregón del interior de los Estados Unidos (var. glauca) iniciaron la brotación en vivero antes que los costeros (var. menziesii). Podría suponerse que las plantas hayan sufrido un estrés por plantación afectando el inicio de crecimiento, no pudiendo evaluar si en el sitio donde se registraron las condiciones climáticas más rigurosas (CET) éstas presentan un mecanismo de tolerancia o un mecanismo de escape al daño provocado por heladas tardías.
O'Neill et al. (11) demostraron la existencia de variación intrapoblacional en progenies de polinización abierta de la var. menziesii (costeras) para poblaciones de la Costa y de las Montañas Cascadas para caracteres adaptativos relacionados con el daño provocado por heladas primaverales en ensayos de vivero bajo condiciones controladas.

Siegfried (8) estableció una relación negativa entre el crecimiento en altura y resistencia al frío en orígenes distribuidos desde British Columbia a California. El mismo autor plantea que modificaciones considerables se producen en el ranking por altura entre los orígenes costeros años tras años. Dentro de los orígenes del interior no se encontraron variaciones clinales, siendo todas más resistentes al frío que las costeras.

En nuestro caso en ambos sitios de ensayo el comportamiento de las distintos procedencias y fuentes de semillas se comparó con testigos comerciales locales de origen desconocido. Estas fuentes de semillas corresponde a una generación de adaptación al clima de la Patagonia. Para la situación del sitio CET, el testigo se comportó de manera similar a los orígenes costeros de los Estados Unidos de mediana elevación, marcando la transición entre los de mediana a baja altitud. Rehfeldt y Gallo (18) sugieren que la raza local tendría su origen a partir de la región costera de los Estados Unidos, de clima suave y templado.

\section{CONCLUSIONES}

La evaluación de procedencias y fuentes semilleras en una etapa temprana, utilizando el criterio de crecimiento en altura como expresión del potencial de crecimiento, podría estar afectando indirectamente y en forma desfavorable características adaptativas de resistencia a heladas tardías.

La intensidad de las heladas ocurridas en uno de los sitios de ensayo ejerció una alta presión de selección que permitió establecer asociaciones significativas y altamente significativas entre el daño provocado por las heladas tardías y el origen de la fuente de semilla. Sin embargo, el buen comportamiento del material proveniente de los Programas de Mejoramiento de EE.UU. y Canadá para las condiciones más severas del sitio CET (ID local 16: $38,9 \%$ daño, ID local 24: $27,8 \%$ daño) de origen costero y el desempeño de algunas procedencias también costeras indican que es 
posible establecer un balance para la selección de procedencias y fuentes de semilla de alto potencial de crecimiento, que a su vez presente cierto grado de tolerancia o resistencia a daños provocados por heladas tardías.

Es necesario continuar con la evaluación del comportamiento a condiciones adversas con el propósito de efectuar los ajustes correspondientes para la elección de los mejores orígenes de semilla en la Región Andino Patagónica. El éxito de la selección dependerá de la evaluación de sucesivos años y de la ocurrencia de heladas que puedan ejercer una marcada intensidad de selección. Ensayar orígenes en sitios muy propensos a la ocurrencia de estos fenómenos o la posibilidad de efectuar pruebas de adaptabilidad a condiciones extremas en laboratorio, sería una excelente herramienta para la obtención de conclusiones más sólidas que respalden estas primeras recomendaciones para la especie en la región.

\section{AGRADECIMIENTOS}

Al doctor Mario Pastorino, por las valiosas sugerencias y correcciones hasta el primer borrador de este trabajo.

\section{BIBLIOGRAFIA}

(1) CORINALDESI, L., L. LA ROSA, S. BRANDAN, D. PINASCO y C. FRISA. Argentina, Sector Forestal. Secretaría de Agricultura, Ganadería y Alimentación. Subsecretaría de Agricultura, Ganadería y Forestación. Dirección de Forestación, 1998, 85 p.

(2) LACLAU, P., L. M. POZO, G. HUERTA, M. MAZZUCHELLI, E. ANDENMATTEN y F. LETOURNEAU. Rentabilidad de la Forestación con Coníferas en Patagonia. Informe Final Proyecto de Investigación (PIA) $N^{\circ}$ 25/96. SAGPyA, Proyecto Forestal de Desarrollo, Programa de Ambito Forestal, INTA, DGByF Provincia de Neuquén, 1999, 121 p.

(3) REY, M., E. ANDENMATTEN y F. LETOURNEAU. Tarifa de volumen para pino oregón (Pseudotsuga menziesii (Mirb) Franco) en la Región Andina de las provincias de Río Negro y Chubut. Actas Cuartas Jornadas Forestales Patagónicas, San Martín de los Andes, Neuquén, UNC, CIEFAP, INTA, SAGYP, PNL APN, SFA, CFN. 24-27 de octubre 1995. Tomo 1, p. 306-311.

(4) ANDENMATTEN, E., M. REY y F. LETOURNEAU. Pino oregón (Pseudotsuga menziesii (Mirb) Franco).
Índice de Densidad de Reineke para la región Andino Patagónica. Comunicación Técnica Área Forestal. Silvicultura, no. 11. Actas Cuartas Jornadas Forestales Patagónicas, San Martín de los Andes, Neuquén; UNC, CIEFAP, INTA-SAGYP, PNL-APN, SFA, CFN; 24 27 octubre 1995. Tomo 1, p. 229-252.

(5) SILEN, R. Genetics of Douglas-fir. USDA Forest Service. Research Paper, WO - 35. 1978, 34 p.

(6) DAVEL, M., C. BARROETAVEÑA y M. RAJCHEMBERG. Muerte del pino oregón por sequía en la Región Andina. CIEFAP, Patagonia Forestal, 1999, Año $\mathrm{V}, \mathrm{N}^{\mathrm{o}} 2$, p. 2-3.

(7) HATTEMER, H. and A. KONIG. Geographic variation of early growth and frost resistance in Douglas-fir. Silvae Genetica 24, 1975, No 4, p. 97-106.

(8) SIEGFRIED, G. Height Growth and Frost Resistance in Douglas-fir Provenances tested in the Northern Part of Germany. IUFRO, Joint Meeting of Working Parties. Vancouver. Canadá. 1978, vol. 2, p. 175-188.

(9) REHFELDT, G. Genetic Variability Within Douglas-fir Populations: Implications for Tree Improvement. Silvae Genetica 32, 1983, p. 9-14.

(10) ENRICCI, J. A. Posibilidades para la forestación en la subregión central del ecosistema andino patagónico. CIEFAP. Publicación Técnica No 14. 1983, 123 p.

(11) O'NEILL, G.; S. AITKEN and T. ADAMS. Genetic selection for cold hardiness in coastal Douglas-fir seedlings and saplings. Canadian Journal Forest Research, 2000, No 30, p. 1.799-1.807.

(12) ANEKONDA, T. Genetics of cold and drought hardiness in coastal Douglas-fir. Workshop Abstracts, Applied Forest Tree Improvement - Genetics, Physiology and Breeding of Forest Trees. Western Forests Genetics Association, 2001, Annual Conference, Davis, California. University Club, Clubroom 1: Thursday, August 2, 2001.

(13) REHFELDT, G. The genetic resource of Douglas-fir in the interior northwest. Interior Douglas-fir the species and its management, Symposium Proceedings, February 27March 1, 1990. Spokane, Washington, USA, p. 53-63.

(14) BUSTOS, C.. Heladas en el sector Precordillerano Nordpatagónico. INTA EEA Bariloche. Comunicación Técnica Recursos Naturales. Agrometeorología, 2001, $\mathrm{N}^{\mathrm{o}} 22,10 \mathrm{p}$.

(15) SERVICIO METEOROLOGICO NACIONAL. Atlas Climatológico de la República Argentina. Buenos Aires, SMN. 1960. pag. varía, mapas.

(16) LINHART, Y. and M. DAVIS. The importance of local genetic variability in Douglas-fir. Symposium Proceedings, February 27 - March 1, 1990. Spokane, Washington, USA, p. 63-71.

(17) REHFELDT, G. Ecological Adaptations in Douglas-fir (Pseudotsuga menziesii var. glauca): a Synthesis. Forest Ecology and Management, 1989, No 28, p. 203-215.

(18) REHFELDT, G. and L. GALLO. Introduction of Ponderosa Pine and Douglas-fir to Argentina. Using quantitative traits for retrospective identification and prospective selection of provenances. New Forest, 2001, $\mathrm{N}^{\circ} 21$, p. 35-44.

(19) SAS INSTITUTE INC., SAS/STAT USER' S GUIDE, Version 6, Fourth Edition, Volume 2, Cary, NC. SAS Institute Inc., 1989, 846 p. 